\title{
DECISÕES FINANCEIRAS FUNDAMENTAIS SÃO TOMADAS NA LEI DE DIRETRIZES ORÇAMENTÁRIAS
}

\author{
Coluna publicada em 18.10.2016: <https://www.conjur.com.br/2016-out-18/ \\ contas-vista-decisoes-financeiras-fundamentais-sao-tomadas-ldo $>$
}

Não obstante recentes notícias sobre o avanço da tramitação e possível aprovação em breve da Lei de Diretrizes Orçamentárias (LDO) com as diretrizes orçamentárias para 2017, ${ }^{1}$ isto acabou ainda não ocorrendo, apesar de já estarmos nos aproximando do final do mês de outubro, praticamente três meses após o prazo constitucionalmente estabelecido (ADCT, art. $35, \$ 2^{\circ}$, I). Mais uma razão para que se volte a chamar a atenção para esse instrumento legislativo sobre o qual já escrevi ${ }^{2}$ e ao qual não se tem dado a devida atenção. E que esperamos não voltem a ocorrer maus exemplos como o que se observou nos últimos anos, em que chegou ao cúmulo de ser aprovada no ano seguinte. ${ }^{3} \mathrm{E}$ também para algumas questôes e decisões importantes no âmbito do Direito Financeiro a ela relacionados.

Cogita-se desta vez de nela fazer constar, como está no texto-base já aprovado na Comissão Mista de Orçamento em 24 de agosto de 2016, a previsão de teto para as despesas públicas, enquanto não se aprova a PEC que pretende dispor de forma definitiva sobre o assunto. ${ }^{4}$ É uma medida que não integra as funções da LDO, e mais uma vez se utilizaria de forma indevida esse instrumento, como meio para inserir disposições de forma provisória na legislação financeira. Convém sempre

1 Sem CPMF, Comissão de Orçamento aprova a LDO 2017. Valor Econômico, 14 de julho de 2016.

2 Coluna $L D O$ é instrumento eficiente para a administração pública, publicada em 9 de abril de 2013 (e que consta deste livro).

3 No caso da LDO para 2015, Lei 13.080, somente publicada em 2.1.2015.

4 Governo Temer faz nova ofensiva contra direitos sociais, desta vez na PLDO 2017. INESC. Disponível em: <http://www.inescr.org.br/noticias >. 
lembrar que a LDO é lei de validade temporária, e não deveria ser um verdadeiro "substitutivo" de leis que tratem de forma geral de matéria orçamentária, como a Lei 4.320. E de aplicação restrita, uma vez que é própria da administração pública federal, não atingindo seus dispositivos as administrações públicas estaduais e municipais.

A questão da fixação de teto para os gastos públicos merece análise mais profunda, mas algumas considerações podem ser adiantadas. A ideia básica da proposta de emenda constitucional que introduz, no ato das disposições constitucionais transitórias, a limitação ao crescimento dos gastos públicos (PEC 241/2016), amplamente noticiada pela imprensa e em discussão no Congresso Nacional, recentemente aprovada em primeira votação, é a instituição do chamado "Novo Regime Fiscal”, com a duração de vinte exercícios financeiros, isto é, vinte anos. Em contraste com as atuais regras de destinação de recursos públicos, o que haveria de propriamente novo com esta alteração da Constituição é a fixação, durante o período de vigência, de limite anual para as despesas primárias de cada um dos Poderes, incluídos o Tribunal de Contas, o Ministério Público e a Defensoria Pública da União. Por definição da emenda, ainda, este limite será vinculado de alguma forma à inflação, com as despesas de um exercício limitadas àquelas realizadas no período anterior, corrigidas pelo IPCA. Estes limites constariam da Lei de Diretrizes Orçamentárias, por determinação constitucional.

É fato que, em situação da grave crise econômica, que exige medidas emergenciais, limitar os gastos públicos, como a que se tem cogitado, pode ser necessária. Certamente não seria caso a legislação vigente, especialmente a Lei de Responsabilidade Fiscal, tivesse sido observada, o que não teria deixado a situação chegar a esse ponto. Mas a irresponsabilidade fiscal dos últimos anos, tantas vezes denunciada nesta coluna, não poderia ter levado a resultado diferente. E é sempre bom ressalvar que estabelecer limites para os gastos de forma linear e generalizada é medida no mínimo imperfeita, certamente causará desajustes e injustiças e poderá frear despesas fundamentais para o pleno desenvolvimento econômico e social, como saúde e educação. Espera-se que ao menos possa "dar para o gasto", como estampa a revista Época na capa da edição desta semana..."

Em face das óbvias dificuldades em aprovar a referida PEC, especialmente em curto prazo e em momento de instabilidade econômica, cogita-se antecipar a medida, inserindo-a desde já na LDO. Como cabe à LDO orientar a elaboração do orçamento anual, pretende-se fixar para 2017 a limitação dos gastos mesmo sem o

Edição 957, de 17 de outubro de 2016. 
acréscimo constitucional, restrita à vigência anual pela própria natureza do instrumento que a veicula. Que tipo de gasto seria, porém, atingido com uma limitação desta natureza? A referência é explícita ao gasto primário, aquele que se destina a financiar as despesas não financeiras do governo, isto é, aquele que não se relaciona com a amortização e o pagamento de juros da dívida pública. Por exemplo, as despesas para o financiamento dos serviços públicos de saúde e educação, os benefícios da previdência e as despesas sociais em geral, constatando-se que a pressão pela redução dos gastos acaba se concentrando naquelas que afetam diretamente o bem-estar da população, o que evidentemente não é desejável.

E também é sempre bom voltar a chamar a atenção para a necessidade de melhoria na gestão pública, verdadeiro foco de vultosos desperdícios de dinheiro público, tema ao qual pouca atenção se dá, como se pode constatar. ${ }^{6}$ Invariavelmente as discussões concentram-se na busca do equilíbrio fiscal pela necessidade de aumentar receitas ou reduzir os gastos por meio de limitaçôes como a que se está propondo, e esquece-se daquela que deve ser a principal medida, qual seja, aumentar a eficiência do gasto, o que permite fazer mais com menos, evitando desperdícios, e permitindo que, sem aumentar a arrecadação, produzam-se melhores resultados para a população. Mas que tendem a gerar efeitos em prazos mais longos, e as situações emergenciais acabam fazendo prevalecer medidas que tendem a "apagar incêndios", perpetuando a "administração-bombeiro" à qual já me referi.

E quando se fala em despesas, esquecem-se outras formas de gastos verdadeiramente "ocultos", como os já chamados "gastos tributários", representados pelos sem-número de benefícios fiscais, nem sempre suficientemente transparentes e por vezes de eficácia duvidosa, sem contar os benefícios creditícios. ${ }^{8}$

Outra despesa de enorme relevância, à qual se deve dar maior atenção e transparência, e ser objeto de debates que permitam decisões mais democráticas, está na dívida pública, que consome parcela elevadíssima do orçamento público, e neste campo a LDO atualmente cumpre importante papel.

6 E sobre o qual já me referi na coluna Não falta dinheiro à administração pública, falta gestão, publicada em 31 de julho de 2012 e que consta neste livro.

7 Direito Financeiro precisa avançar, e a hora é agora, publicada em 31 de maio de 2016.

8 Vide as operações do BNDES, já mencionadas na coluna BNDES tem o dever de colaborar com a transparência dos gastos públicos, publicada em 17 de novembro de 2015 (e que consta neste livro). As "equalizações" do Plano Safra, que tanto problema têm dado na questão do impeachment, e outras. A questão também foi bem observada pelo jornalista José Paulo Kupfer em coluna publicada recentemente (Balança desequilibrada. Estadão, 10 de outubro de 2016). E foi manchete da Folha de S.Paulo de 16 de outubro de 2016: "Bolsa-empresário" resiste ao ajuste fiscal em 2017. 
Alguns argumentos apontam para a inconveniência de restringir, por determinação normativa, o gasto com juros, pois isso comprometeria um dos principais instrumentos de condução da política monetária e de controle da inflação, além de promover interferências nem sempre eficazes em valores que são preços determinados pelo mercado. Como aponta o economista Samuel Pessoa, a estratégia para reduzir o custo da dívida pública (ou seja, reduzir os gastos financeiros do governo) não passa ao largo da questão fiscal, mas é por ela influenciada: o controle do gasto primário representa um indicador de solvência do Estado que, refletindo-se nas expectativas dos credores atuais e potenciais, reduz o preço cobrado para lhe emprestar dinheiro. Em síntese, "a redução do gasto primário causa queda do gasto financeiro. $\mathrm{O}$ contrário não ocorre. Em geral acontece o inverso: redução do gasto financeiro induz, por meio de escolhas do Congresso Nacional, a aumento do gasto primário"?

Sendo assim, nada mais razoável do que decidir democraticamente sobre essa despesa, e a melhor oportunidade para fazê-lo está justamente na LDO.

Um dos dispositivos da LDO que tem assumido maior relevância atualmente é justamente o que cumpre a função de estabelecer as metas de resultado nominal e primário e montante da dívida pública referentes ao exercício financeiro a que se refere e aos dois subsequentes, ${ }^{10}$ e ao fixar as metas de resultado para o exercício financeiro subsequente, tem balizado todo o gasto público.

A LDO, como as demais leis de natureza orçamentária, é de iniciativa privativa do Chefe do Poder Executivo, a quem cabe formular sua proposta. Mas, é sempre bom lembrar, é aprovada pelo Legislativo, a quem cabe a palavra final a respeito. Sendo assim, a fixação da meta de resultado tem uma importância ímpar, cuja decisão deve ser tomada pelos representantes eleitos, inicialmente o Chefe do Poder Executivo e definitivamente pelo Parlamento, que devem abrir o debate e, de forma democrática e transparente, definir este valor, que terá substancial relevância na questão da dívida pública, sendo este o principal momento em que se poderá discutir esta questão que hoje é fundamental. Até porque, por ocasião da votação da lei orçamentária anual, uma vez proposta, não mais será permitido ao Poder Legislativo emendá-la no que tange ao serviço da dívida, em face da vedação constitucional do art. $166, \S 3^{\circ}$, II, $b$.

9 PESSÔA, Samuel. E os juros?. Folha de S.Paulo, 26 de junho de 2016.

10 LRF, art. $4^{\circ}, \$ 1^{\circ}$ : "Integrará o projeto de lei de diretrizes orçamentárias Anexo de Metas Fiscais, em que serão estabelecidas metas anuais, em valores correntes e constantes, relativas a receitas, despesas, resultados nominal e primário, e montante da dívida pública, para o exercício a que se referirem e para os dois seguintes". 
Esse dispositivo inclusive fundamentou uma das acusações que deram origem ao pedido de impeachment da Presidente, pois a abertura de crédito adicional em montante superior ao que previa a meta de superávit primário fixada pela LDO era uma das restrições que foram descumpridas. O que só demonstra a relevância cada vez maior que hoje assume no âmbito das finanças públicas.

Vê-se, pois, tratar-se de decisão que precisa ser tomada com base em informações claras, abrangentes e confiáveis, submetidas a amplo debate, com transparência, a fim de que seja respeitada, para que não seja mais alterada posteriormente, como ocorreu várias vezes nos últimos anos, destruindo completamente a sua credibilidade, e tornando a meta fixada pela LDO uma verdadeira "mentira fiscal", como já me referi anteriormente. ${ }^{11}$

Outro dispositivo ao qual não se tem dado a devida atenção é fundado no art. $9^{\circ}, \$ 2^{\circ}$, da Lei de Responsabilidade Fiscal, que permite à LDO ressalvar despesas suscetíveis de contingenciamento, o que as privilegia na fase de execução orçamentária. Uma forma de tornar claras as prioridades. A importância deste dispositivo é particularmente grande, dadas algumas peculiaridades do orçamento brasileiro, em que as legítimas opções políticas pelas despesas a serem realizadas durante o exercício são feitas não apenas no momento em que a lei orçamentária é elaborada, mas também naquele em que ela é executada. Esta fase não tem se constituído apenas como uma etapa de aplicação dos montantes previstos, mas, desde que se entenda que as dotações constituem um teto, na execução do orçamento tomam-se diversas decisões acerca da oportunidade e conveniência de se realizarem determinados gastos, muitas vezes optando por suspender a aplicação dos recursos previstos para assegurar melhores resultados. ${ }^{12} \mathrm{E}$ o mencionado dispositivo da Lei de Responsabilidade Fiscal oferece ao legislador a faculdade de incluir determinadas despesas imunes ao contingenciamento, dada a relevância conferida a estes gastos. $\mathrm{O}$ anexo da LDO que vier a estabelecer esta proteção permite, portanto, oferecer maior estabilidade a algumas despesas no momento da execução.

A LDO teve suas funções ampliadas para além das funçôes constitucionalmente definidas, em muito se descolando de seu propósito original: orientar a elaboração do orçamento anual a partir da definição de grandes prioridades. ${ }^{13}$ Weder

11 Desrespeito ao Direito Financeiro afastou Dilma do cargo de Presidente, publicada em 12 de maio de 2016 e que consta neste livro.

12 Já discorri sobre o tema na coluna Orçamento não pode mais ser uma peça de ficção, publicada em 2 de junho de 2015 (e que consta neste livro.).

13 Como já afirmei em outra coluna Direito Financeiro precisa avançar, e a hora é agora, publicada em 31 de maio de 2016. 
de Oliveira analisa a gênese desta lei especial e aponta o contraste entre o propósito inicial, destinado a oferecer orientação de alto nível, a partir de grandes números, à lei orçamentária, e a feição efetivamente tomada pela atuação do legislador. Se é verdade que as leis de diretrizes orçamentárias muitas vezes se dedicam a preencher lacunas da legislação complementar e a determinar procedimentos de elaboração orçamentária, de outro lado há um aspecto relevante desempenhado por esta lei ao guiar o orçamento a partir de uma grandeza relevante: as metas de resultado do governo. Como sintetiza o autor citado, "[d]isso resulta que, com exceção do tema meta de resultado primário, a função 'orientar a elaboração da lei orçamentária anual' seja desempenhada intensamente em outras perspectivas, que se poderiam dizer regulatórias, procedimentalistas e microalocativas, e que têm interessado mais aos congressistas". ${ }^{14}$

Espera-se que se dê mais atenção e seriedade à LDO, permitindo assim que democraticamente sejam tomadas decisões fundamentais, como a definição das prioridades dos gastos públicos, dimensão do esforço a ser feito para o pagamento da dívida e outras que, neste momento de crise, exigem que todos participem da definição de quais serão os sacrifícios e quem serão os prejudicados e beneficiados.

14 OLIVEIRA, Weder de. Gênese, funcionalidade e constitucionalidade da Lei de Diretrizes Orçamentárias. São Paulo: Fadusp, 2016. p. 415. 